\title{
Nanomechanical sampling of material for nanoscale mass spectrometry chemical analysis
}

Citation for published version (APA):

Ovchinnikova, O. S., Lorenz, M., Wagner, R. B., Heeren, R. M. A., \& Proksch, R. (2021). Nanomechanical sampling of material for nanoscale mass spectrometry chemical analysis. Analytical and Bioanalytical Chemistry, 413(10), 2747-2754. https://doi.org/10.1007/s00216-020-02967-0

Document status and date:

Published: 01/04/2021

DOI:

10.1007/s00216-020-02967-0

Document Version:

Publisher's PDF, also known as Version of record

Document license:

Taverne

Please check the document version of this publication:

- A submitted manuscript is the version of the article upon submission and before peer-review. There can be important differences between the submitted version and the official published version of record.

People interested in the research are advised to contact the author for the final version of the publication, or visit the DOI to the publisher's website.

- The final author version and the galley proof are versions of the publication after peer review.

- The final published version features the final layout of the paper including the volume, issue and page numbers.

Link to publication

\footnotetext{
General rights rights.

- You may freely distribute the URL identifying the publication in the public portal. please follow below link for the End User Agreement:

www.umlib.nl/taverne-license

Take down policy

If you believe that this document breaches copyright please contact us at:

repository@maastrichtuniversity.nl

providing details and we will investigate your claim.
}

Copyright and moral rights for the publications made accessible in the public portal are retained by the authors and/or other copyright owners and it is a condition of accessing publications that users recognise and abide by the legal requirements associated with these

- Users may download and print one copy of any publication from the public portal for the purpose of private study or research.

- You may not further distribute the material or use it for any profit-making activity or commercial gain

If the publication is distributed under the terms of Article $25 \mathrm{fa}$ of the Dutch Copyright Act, indicated by the "Taverne" license above, 


\title{
Nanomechanical sampling of material for nanoscale mass spectrometry chemical analysis
}

\author{
Olga S. Ovchinnikova ${ }^{1}$ (D) Matthias Lorenz ${ }^{1,2} \cdot$ Ryan B. Wagner $^{3} \cdot$ Ron M. A. Heeren $^{4} \cdot$ Roger Proksch $^{5}$
}

Received: 17 June 2020 /Revised: 3 September 2020 / Accepted: 21 September 2020 / Published online: 6 October 2020

(C) Springer-Verlag GmbH Germany, part of Springer Nature 2020

\begin{abstract}
The ability to spatially resolve the chemical distribution of compounds on a surface is important in many applications ranging from biological to material science. To this extent, we have recently introduced a hybrid atomic force microscopy (AFM)-mass spectrometry (MS) system for direct thermal desorption and pyrolysis of material with nanoscale chemical resolution. However, spatially resolved direct surface heating using local thermal desorption becomes challenging on material surfaces with low melting points, because the material will undergo a melting phase transition due to heat dissipation prior to onset of thermal desorption. Therefore, we developed an approach using mechanical sampling and collection of surface materials on an AFM cantilever probe tip for real-time analysis directly from the AFM tip. This approach allows for material to be concentrated directly onto the probe for subsequent MS analysis. We evaluate the performance metrics of the technique and demonstrate localized MS sampling from a candelilla wax matrix containing UV stabilizers avobenzone and oxinoxate from areas down to $250 \mathrm{~nm} \times 250 \mathrm{~nm}$. Overall, this approach removes heat dissipation into the bulk material allowing for a faster desorption and concentration of the gas phase analyte from a single heating pulse enabling higher signal levels from a given amount of material in a single sampling spot.
\end{abstract}

Keywords Mechanical sampling $\cdot$ Thermal desorption $\cdot$ Nanometer scale $\cdot$ Atmospheric pressure $\cdot$ Atomic force microscopy $\cdot$ Mass spectrometry $\cdot$ Atmospheric pressure chemical ionization

\section{Introduction}

The structure-function relationship in systems ranging from additives in adhesives and soft materials to cellular function in

This manuscript has been authored by a contractor of the US Government under contract DE-AC05-00OR22725. Accordingly, the US Government retains a paid-up, nonexclusive, irrevocable, worldwide license to publish or reproduce the published form of this contribution, prepare derivative works, distribute copies to the public, and perform publicly and display publicly, or allow others to do so, for US Government purposes.

Published in the topical collection Mass Spectrometry Imaging 2.0 with guest editors Shane R. Ellis and Tiffany Porta Siegel.

Electronic supplementary material The online version of this article (https://doi.org/10.1007/s00216-020-02967-0) contains supplementary material, which is available to authorized users.

Olga S. Ovchinnikova

ovchinnikovo@ornl.gov

1 Center for Nanophase Materials Sciences, Oak Ridge National Laboratory, Oak Ridge, TN 37831-6493, USA

2 University of Tennessee, Knoxville, Knoxville, TN 37996, USA biological systems is often defined by chemical segregation that occurs at the nanoscale. However, chemical composition in these materials is routinely studied using bulk analysis approaches like liquid and gas chromatography (LC and GC) coupled with mass
3 School of Mechanical Engineering, Purdue University, West Lafayette, IN 47907, USA

4 Maastricht Multimodal Molecular Imaging Institute (M4I), Maastricht University, 6200 MD Maastricht, The Netherlands

5 Asylum Research an Oxford Instruments Company, Santa Barbara, CA 93117, USA 
spectrometry and optical spectroscopy that average the chemical information over the whole sample losing valuable information about chemical localization and local structure that can have profound effects on material functionality ranging from material elasticity to photovoltaic performance. Therefore, a lot of effort has been dedicated to developing spatially resolved techniques that allow to correlate physical and functional material properties with chemically sensitive approaches like infrared (IR), Raman and time-resolved optical spectroscopy, and fluorescence and mass spectrometry [1]. However, spatially resolved mass spectrometry-based chemical imaging techniques that provide localized chemical mapping, such as matrix-assisted laser desorption ionization (MALDI) [2] and secondary ion mass spectrometry (SIMS) [3], are usually performed in vacuum environments requiring either complicated sample preparation or preclude certain volatile species from being analyzed all together. To circumvent the need to place a sample in a vacuum environment for spatially resolved chemical imaging, attention has focused on developing ambient mass spectrometry imaging approaches [4]. With this in mind, we have demonstrated the use of proximal probe thermal desorption/ionization combined with mass spectrometry (TD/I-MS) for spatially resolved chemical profiling and imaging of surfaces under ambient conditions [5-11]. This surface sampling/ionization and analysis approach uses a heated probe tip placed in close proximity to or in contact with a surface to locally desorb intact molecular species or pyrolysis products from a surface that are then ionized by an atmospheric pressure ionization source like electrospray ionization (ESI) or atmospheric pressure chemical ionization (APCI) and analyzed using MS.

To improve on the spatial resolution of the sampling technique to the nanoscale and allow for correlated structurechemical functionality analysis, we employed the use of heated atomic force microscope (AFM) probes on a coupled AFM-MS platform $[6-8,10]$. These works build on that of Reading and coworkers [12-16] where they used 5- $\mu$ m-tipdiameter Wollaston wire heated probes to perform both point thermal desorption and pyrolysis, capturing the liberated vapor material then injecting it into a gas chromatograph mass spectrometer (GC/MS) for separation, electron ionization (EI), and mass analysis from desorption craters approximately $6 \mu \mathrm{m}$ in diameter and $1.7 \mu \mathrm{m}$ deep. Using much smaller, 30-nm-diameter AFM probes, we were able to demonstrate direct sampling on the AFM-MS systems from desorption craters $250 \mathrm{~nm}$ in diameter and $100 \mathrm{~nm}$ deep from caffeine and yellow ink thin films where the mass spectral signal from each desorption event recorded in real time [7, 10]. Most recently, we demonstrated the ability to obtain co-registered mass spectral chemical images with AFM topographical as well as mechanical images from inked patterns on paper [6], living bacterial colonies on an agar gel [6], phase-separated polymers [8], additives in adhesives, and active ingredients in personal care products directly on hair [17].
However, when performing direct thermal desorption or pyrolysis by the heated probe from certain material types, it can be difficult to limit the sampling volume, thus limiting the spatial resolution achievable in either a chemical profiling or imaging mode. This is because material surfaces with low melting points will undergo a melting phase transition due to heat dissipation prior to the onset of thermal desorption [18]. This physical dissipation of heat into the material is a relatively slow process occurring on the time scale of milliseconds causing a much larger area than the diameter of the tip to become damaged by the heating process. We have demonstrated that through the use of rapid tailored heating pulses to an AFM cantilever, it is possible have a $381 \times$ improvement in the desorption efficiency and an $8 \times$ improvement in lateral spatial resolution compared with the conventional heating approaches on material surfaces like printed inks that undergo a melting transition prior to desorption [10]. An alternative approach to direct heating is to mechanically sample the surface with the AFM probe tip, remove the tip from close proximity of the surface, and subsequently thermally desorb material from the tip for mass spectral analysis. This enables very small areas of the surface to be analyzed, minimizing damage of the surface and maximizing the localization of chemical properties.

Mechanical, thermal, and laser-assisted nanosampling with scanning probes for subsequent chemical analysis on the probe tip or elsewhere by means of various optical spectroscopy and mass spectrometry approaches has been shown as a successful route towards multimodal chemical imaging [1, 13, 19-21]. However, all previous MS approaches required to mechanically transfer material from the surface of the AFM tip to a separate and subsequent mass spectrometry analysis platform before revealing the material that was captured on the probe.

Herein, we report on mechanical sampling and collection of surface materials on an AFM probe tip for real-time analysis directly from the tip. This approach allows for material to be concentrated directly onto the probe from areas down to $250 \mathrm{~nm} \times 250 \mathrm{~nm}$ enabling sampling of waxy and volatile materials that would not be amenable to direct thermal desorption. We demonstrate the effect of force to maximize on sample collection. Additionally, this approach allows heat to be transferred faster into the sampled volume by minimizing on heat dissipation into the bulk material allowing for a faster desorption and concentration of the gas phase analyte from a single heating pulse enabling higher signal levels from a given amount of material in a single sampling spot.

\section{Materials and methods}

\section{Chemicals}

Candelilla wax matrix containing UV stabilizers avobenzone $3 \%$ and oxinoxate $7.5 \%$ was purchased locally in the form of 
ChapStick ${ }^{\circledR}$ lip balm and was applied directly to a glass cover slide mounted on an AFM sample puck. A thin film on the lip balm was created by wiping away excess wax with a Kimwipe. Neat avobenzone was purchased from SigmaAldrich (St. Louis, MO) and headspace sampling of volatile vapor was performed to obtain the MS/MS spectra of the avobenzone standard. Healthy mouse kidneys were obtained from Maastricht University in accordance with protocols approved by the Animal Care and Use Committee under Animal Experiment Committee (DEC) number 2016-006 AVD107002016720. Twelve-micrometer-thick sections were prepared using a cryomicrotome (Leica, Nussloch, Germany) at $-20{ }^{\circ} \mathrm{C}$ and thaw-mounted on ITO-coated glass slides. Samples were stored at $-80{ }^{\circ} \mathrm{C}$ until shipment to the USA on dry ice.

\section{Experimental setup}

The AFM-MS experimental setup has been described in detail previously $[8,10,17]$. Here, we used both a Veeco Multimode AFM (Bruker AXS, Santa Barbara, CA) equipped with a closed-loop N-Point stage (N-Point, Madison, WI) and a Nanonis system controller (SPECS Zurich GmbH, Zurich, Switzerland) for resistive thermal desorption coupled to a Thermo Fisher Scientific LTQ XL (Thermo Fisher Scientific, Bremen, Germany), as well as Asylum Research Cypher ES (Asylum Research, Santa Barbara, CA) with blueDrive for photothermal desorption coupled with a Thermo Fisher Scientific Orbitrap Velos Pro (Thermo Fisher Scientific, Bremen, Germany) that was used to obtain the nanometer-scale topographical images and to control the nanoscale thermal desorption spot sampling. Material was thermally desorbed from the surface using VITA-MMNANOTA-300 nanothermal analysis (TA) AFM probes (Bruker AXS, Camarillo, CA) as well as NanoSensors PtSiFM-SPL (NanoWorld, Neuchâtel, Switzerland) AFM probes. Temperature calibration of the AFM probes was carried out using a voltage ramp across standard polymeric samples polycarbolactone (PCL), high-density polyethylene (HDPE), and poly(ethylene terephthalate) (PET) with known melting temperatures $[22,23]$ by calibrating the dynamic transfer function, a technique first introduced by Lee et al. [24].

Desorbed and ionized species were monitored with full scan mass spectra and MS/MS product ion spectra (avobenzone transition $\mathrm{m} / \mathrm{z}, 311 \rightarrow 0$, normalized collision energy 35\%). For TD measurements over an array of points, the AFM was controlled using custom software that allowed for independent variation of the force-feedback set-point of the cantilever and the position of the tip across the sample surface. The mass spectrometer and the AFM were set up with the AFM serving as the master controller for the timing sequences.

\section{Results}

Materials like waxes and tissue samples have large temperature differences between material damage and thermal desorption. As seen in Electronic Supplementary Material (ESM) Fig. S1 when sampling directly using an AFM probe for thermal desorption from a candelilla wax matrix containing UV stabilizers avobenzone $3 \%$ and oxinoxate $7.5 \%$, the affected melt area is on the order of $50 \mu \mathrm{m}$, limiting the ability to perform spatially resolved imaging using an AFM-MS platform. To get around the heat dissipation problem of conventional thermal desorption surface sampling, where the AFM tip is engaged on the surface and heat is transferred from the probe into the material causing thermal desorption (Fig. 1a), we have implemented nanomechanically assisted sample pick-up followed by thermal desorption with secondary ionization by APCI and mass spectral detection, "scratch and sniff" (Fig. 1b). In the "scratch and sniff" process as depicted in Fig. 1b, the AFM tip is used to mechanically remove material from the surface with subsequent thermal desorption of the material from the tip when it is withdrawn from the surface. Using the AFM tip to mechanically collect material onto the tip allows the sampling of low melting point materials with high spatial resolution without physically altering a large area of the material surface as seen in Fig. S1 (see ESM). In this process, the area that is sampled directly correlates to the area that the AFM probe scanned on the surface. Figure $1 \mathrm{~b}$ demonstrates the steps involved in the sampling process: engaging tip on the surface and raster scanning the tip over a surface (I), tip with material accumulated on it is withdrawn from the surface (II), and tip is heated to promote thermal desorption of material accumulated on the tip (III). To confirm material collection onto the probe, before and after nanomechanical surface sampling, topography images were acquired for the candelilla wax surface, a very low melting point material. Figure 1c, d, and e show topography images of before, during, and after nanomechanical sampling from a $2.5 \mu \mathrm{m} \times 2.5 \mu \mathrm{m}$ area from the same candelilla wax matrix as in Fig. S1 (see ESM) however now with a controllable collection process. As can be seen in Fig. 1e although the majority of material seems to be removed from the scanned area, some material accumulation can be seen to the left and right boundaries of where the AFM tip scanned. The material buildup to the left and right of the scan direction supports the assumption that there is a limited amount of material that can be accumulated on the current AFM probe designs. However, tailored probe geometries could be envisioned that would enable more material to be collected on the probe during scanning.

Nanomechanical sample pick-up relies on material being picked up by the AFM tip caused by scanning the AFM tip across the surface in contact mode. Therefore, applying additional force onto the AFM tip as it scans across the surface improves the collection efficiency. Figure 2 a shows the 
Fig. 1 Schematic illustration of experimental flow for (a) direct heating thermal desorption: (I) a non-heated AFM probe is positioned above the surface and subsequently is engaged onto the surface, (II) voltage is applied to the AFM tip causing the tip to heat up, (III) thermal diffusion from the heated AFM tip into the substrate produces a thermal desorption of the material. (b) Nanomechanical assisted sample pick-up and removal followed by thermal desorption: (I) a nonheated AFM probe is rastered across a surface to collect materials onto the AFM tip, (II) the AFM tip is subsequently removed from the surface bringing with it material collected on the surface, (III) voltage is applied to the AFM tip causing it to heat up and thermally desorbing the material that was collected on the probe.

Topography images of the UV stabilizer avobenzone in candelilla wax matrix (c) before, (d) during, and (e) after nanomechanical sample pick-up. Material was removed during raster scanning processes; dashed square highlights area of removed material

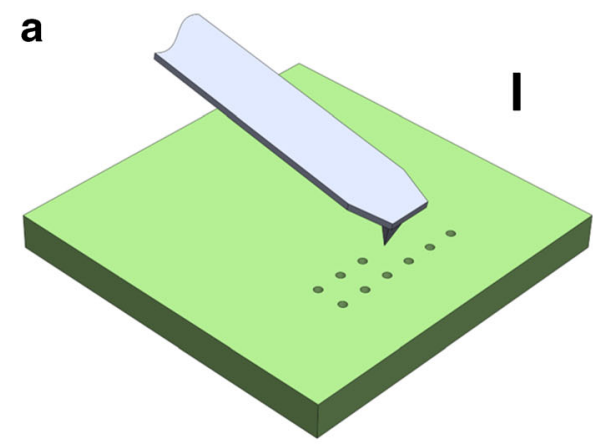

b
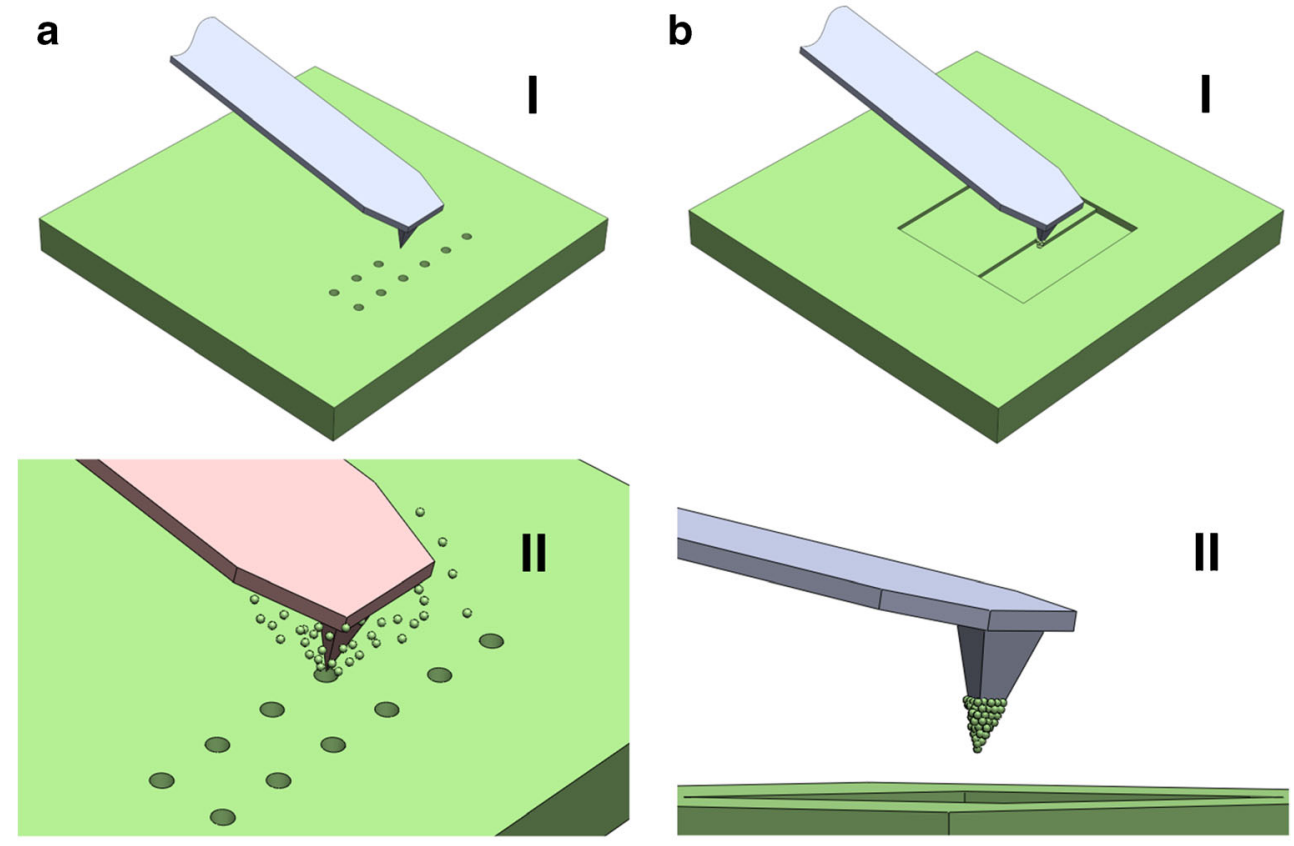

II
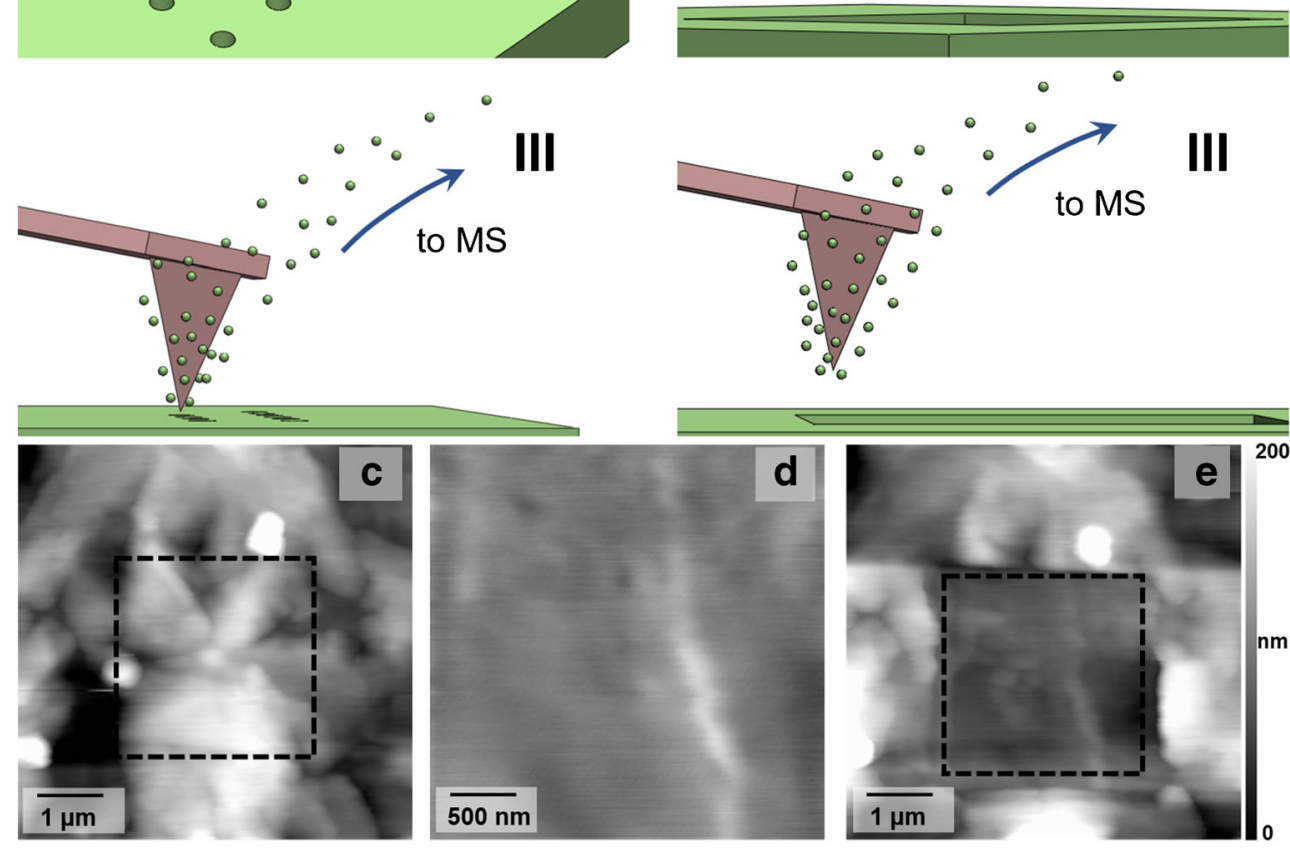

to MS

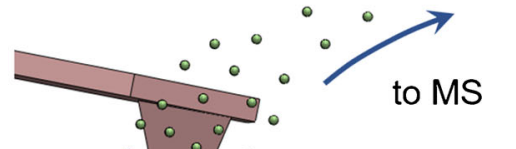

III

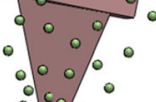
$: c^{\circ}$ $0 \%$
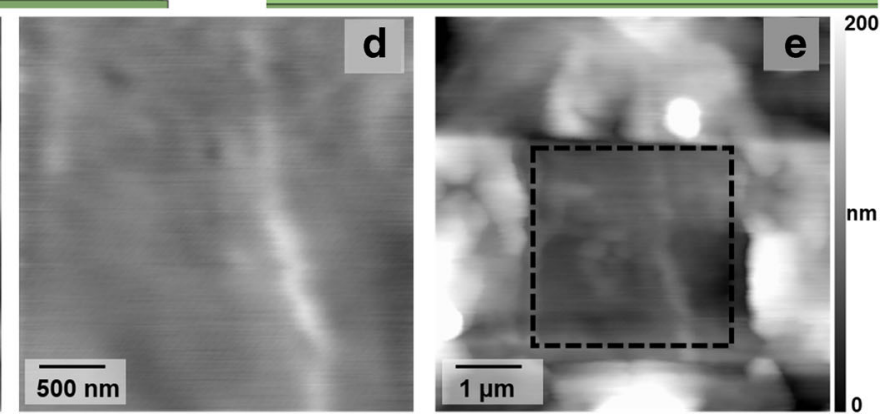

relative integrated mass spectral peak areas of $\mathrm{m} / \mathrm{z}, 135$ and $\mathrm{m} / \mathrm{z}$ 161, MS/MS products of UV stabilizer avobenzone, $\mathrm{m} / \mathrm{z}$ $311 \rightarrow \circ$, CE 35 , in a candelilla wax matrix as a function of force applied to the AFM cantilever. The increase in peak area is due to the change in intensity of the ion signal as the peak widths in the extracted ion chronograms are determined by the length of the heating pulses applied to AFM cantilever that are kept constant with all experiments. Force applied to the scanning cantilever causes the AFM tip to penetrate deeper into the surface causing an increase in the amount of collected material that is proportional to the surface area of the tip in contact with the surface. Since the AFM tip has a pyramidal structure, the amount of material collected onto the tip has a nonlinear relationship with the applied force onto the cantilever. More importantly, the data in Fig. 2a demonstrate that a certain amount of force is necessary to push the AFM tip into the surface to improve sample collection. For our sample surface, a minimum of $\sim 2 \mu \mathrm{N}$ of force was required for the AFM tip to penetrate the surface versus just scanning over the surface.

In addition to the effect of applied force on the AFM cantilever to the amount of material collected, the relationship between the scanned area and the mass spectral signal area of avobenzone was explored for scanned areas ranging $250 \mathrm{~nm} \times 250 \mathrm{~nm}$ to $5 \mu \mathrm{m} \times 5 \mu \mathrm{m}$ in size (Fig. 2b). Although a linear relationship between the scanned area and the relative mass spectral peak area would be expected, because the AFM tip has a limited surface area for material to collect on, saturation in the mass spectral response can be seen 

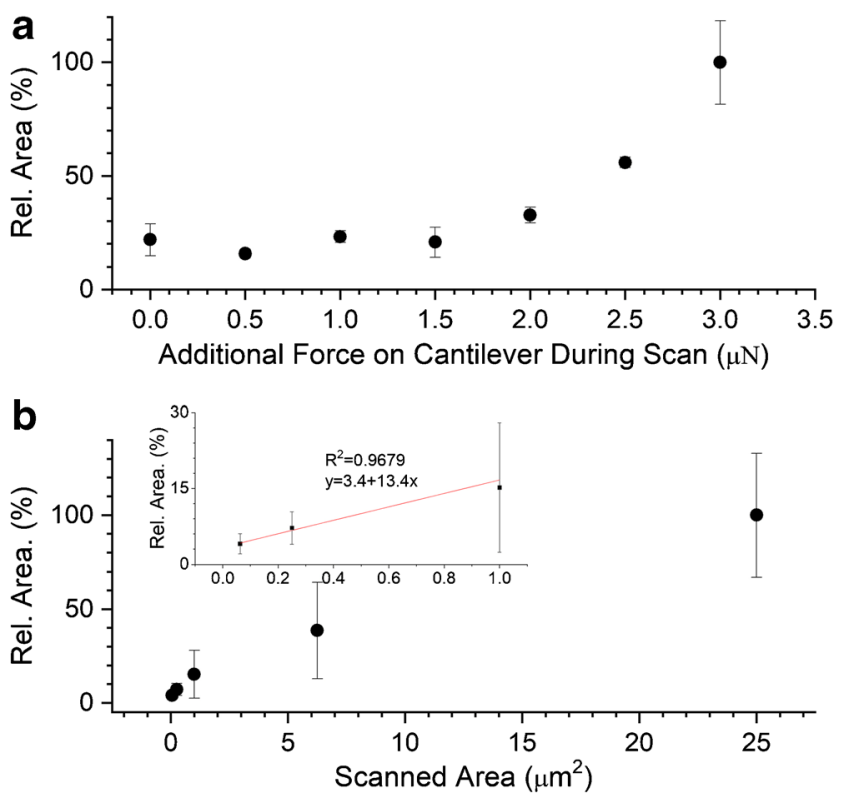

Fig. 2 Optimization of parameters for the UV stabilizer avobenzone in a candelilla wax matrix using nanomechanical sample pick-up followed by TD relative to the integrated mass spectral peak areas of $\mathrm{m} / \mathrm{z}, 135$ and $\mathrm{m} / \mathrm{z}$. $161, \mathrm{MS} / \mathrm{MS}$ products of UV stabilizer avobenzone, $\mathrm{m} / \mathrm{z}, 311 \rightarrow \circ, \mathrm{CE} 35$ as a function (a) of force applied to the cantilever while scanning $500 \mathrm{~nm} \times 500 \mathrm{~nm}$ area, (b) size of the scanned area while applying $3 \mu \mathrm{N}$ of force to the tip. Scan speed was $0.5 \mathrm{~Hz}$ per line with 128 lines for each area; TD probe temperature was $450{ }^{\circ} \mathrm{C}$. Error bars represent \pm 1 standard deviation from 3 replicate samplings

for sampled areas that are larger than $1 \mu \mathrm{m} \times 1 \mu \mathrm{m}$ in size. However, as can be seen from the inset in Fig. $2 b$, for sampled areas between $250 \mathrm{~nm} \times 250 \mathrm{~nm}$ and $1 \mu \mathrm{m} \times 1 \mu \mathrm{m}$, a linear signal relationship is observed, further supporting the notion that the surface area of the AFM tip in contact with the surface plays an important role in determining how much material can be accumulated on the probe. Therefore, if we assume that a standard AFM probe is pyramidal with a tip height of $\sim 4 \mu \mathrm{m}$ and each side width of $\sim 2.5 \mu \mathrm{m}$, the exposed surface area of a tip that is fully penetrated into a surface is $\sim 21 \mu \mathrm{m}^{2}$. Since we expect the AFM probe to not sink completely into the material, the actual exposed surface area will be less than $21 \mu^{2}$ and be proportional to the square of penetration depth of the tip into the surface. Furthermore, the limited surface area of the tip will also lead to greater uncertainty in the reproducibility of the sampling values. Once all the exposed surfaces are covered with material, it is possible to accumulate multiple layers of material on the probe, but such material accumulation would most likely be less stable and reproducible from scan to scan leading to large error bars seen in Fig. $2 b$ on the larger sampling areas. Overall, the volume of the sampled material is likely to correlate directly with signal strength; however, few factors that complicate this analysis are (i) unknown tip shape and the interplay between that and the sample plasticity and hardness, along with the milled material tip adhesion, will all affect the amount of material extracted and
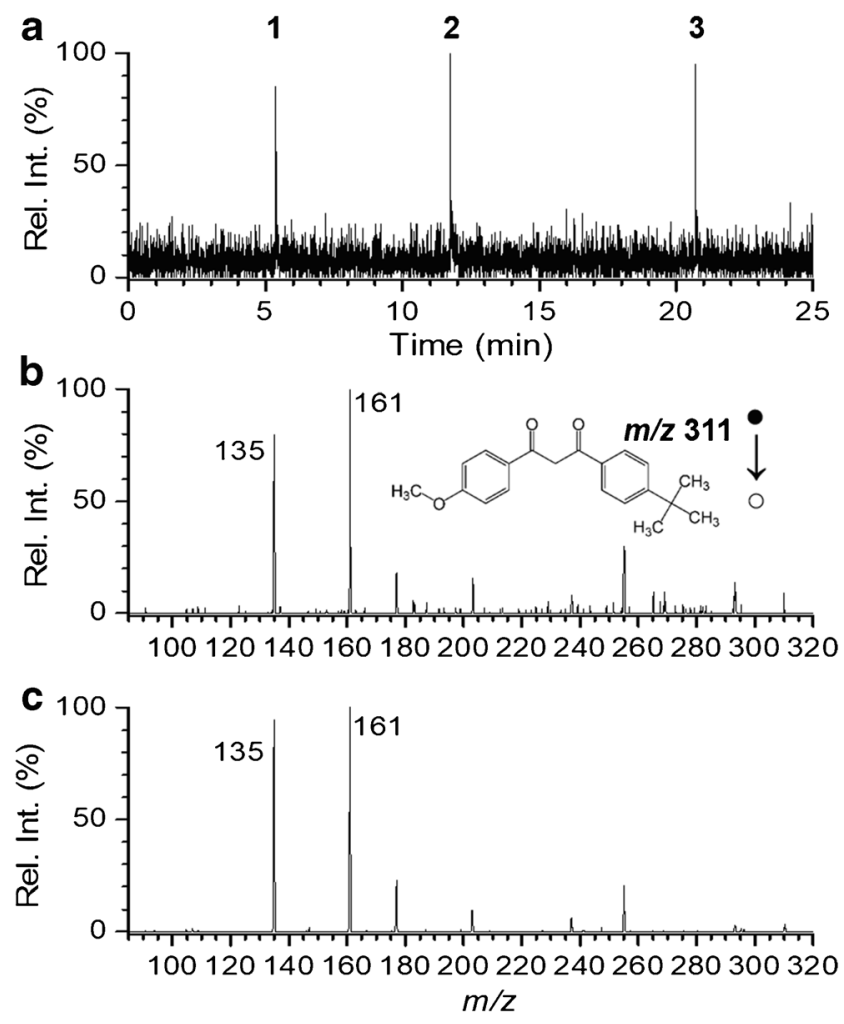

Fig. 3 Spatially resolved sampling of the UV stabilizer avobenzone in a candelilla wax matrix using nanomechanical sample pick-up followed by TD (a) extracted ion current of $\mathrm{m} / \mathrm{z}, 161$ for three replicate $500 \mathrm{~nm} \times$ $500 \mathrm{~nm}$ using $3 \mu \mathrm{N}$ of force applied to the tip, (b) background subtracted MS/MS (m/z,311 $\rightarrow$ o, CE 35) spectra from sampling "2" shown in panel (a), inset shows structure of avobenzone, and (c) background subtracted MS/MS spectra of avobenzone standard

therefore the signal strength and (ii) if the sample region is heterogeneous, it is not necessarily clear that increasing the milled volume will increase the amount of analyte that makes its way to the mass sprectrometer. Work on nanomilling of material and the correlation with depth and material removal, especially in complex materials, is as of today still an active research area and deserves more exploration $[25,26]$.

The sampling reproducibility for areas less than $1 \mu \mathrm{m}^{2}$ is demonstrated in Fig. 3a from 3 subsequent samplings of $500 \mathrm{~nm} \times 500 \mathrm{~nm}$ areas. Figure $3 \mathrm{a}$ shows the extracted ion chronogram for $\mathrm{m} / \mathrm{z} 135$ and $\mathrm{m} / \mathrm{z} 161$, the main fragments for avobenzone, which is the UV stabilizer in the candelilla wax matrix. As can be seen in Fig. 3b, the quality of the associated mass spectra for avobenzone that is $3 \%$ by weight matches very well with that of the avobenzone standard analyzed via head space sampling in Fig. 3c. Additionally, the reproducibility of collecting material from three subsequent $500 \mathrm{~nm} \times 500 \mathrm{~nm}$ samplings seen in Fig. 3a points to the uniform distribution of the $3 \%$ avobenzone active ingredient in the wax matrix. Figure $3 \mathrm{a}$ and $\mathrm{b}$ also highlight that minimizing heat dissipation into the bulk material allows for a 
faster desorption and concentration of the gas phase analyte from a single heating pulse, enabling higher signal levels from a given amount of material in a single sampling spot, i.e., clear mass spectra of $3 \%$ avobenzone from a $500 \mathrm{~nm} \times 500 \mathrm{~nm}$ sampling. The minimum sampling volume for avobenzone in the candelilla wax was calculated using three different analytical approaches shown in Fig. S2 and Table S1 (see ESM) using volume data calculated from the AFM images of the removed material and integrated signal for avobenzone, and was found to be between $0.0205 \mu^{3}$ and 0.108 . Using the $0.108 \mu \mathrm{m}^{3}$ volume estimate and the known $3 \%$ concentration of avobenzone in the candelilla wax matrix produced a limit of detection (LOD) of 7.4 amol for avobenzone (ESM Table S2). It should be noted that this number is in good agreement with other thermal desorption and laser vaporization ambient surface sampling mass spectrometry approaches with a 4-amol LOD for agrochemical ametryn reported for pin-to-capillary flowing atmospheric pressure afterglow (FAPA) ion source [27] and 2-amol LOD for lysine using laser desorption/ ionization droplet delivery mass spectrometry (LDIDD-MS) [28]. An in-depth review of quantitation using various ambient desorption and ionization mass spectrometry approaches by Shelley et al. [29] provides a summary of the limits of detection for all the techniques and a perspective on the challenges to take ambient mass spectrometry from a qualitative screening to an accurate quantification tool.

To demonstrate the universality of the "scratch and sniff" to a wider class of materials and thermal desorption approaches, we performed nanomechanical sampling directly from a mouse kidney thin tissue sample followed by direct photothermal desorption from the AFM tip. Figure 4a shows the AFM topography of the kidney tissue prior to sampling while Fig. $4 \mathrm{~b}$ and $\mathrm{c}$ show the topography of the surface after a $1 \mu \mathrm{m} \times 1 \mu \mathrm{m}$ box was scanned to remove material. As with the wax sample surface, some material buildup can be seen along the edges of the scanned area indicating that methodologies that enable higher collection efficiencies need to be explored in the future. The corresponding full scan background
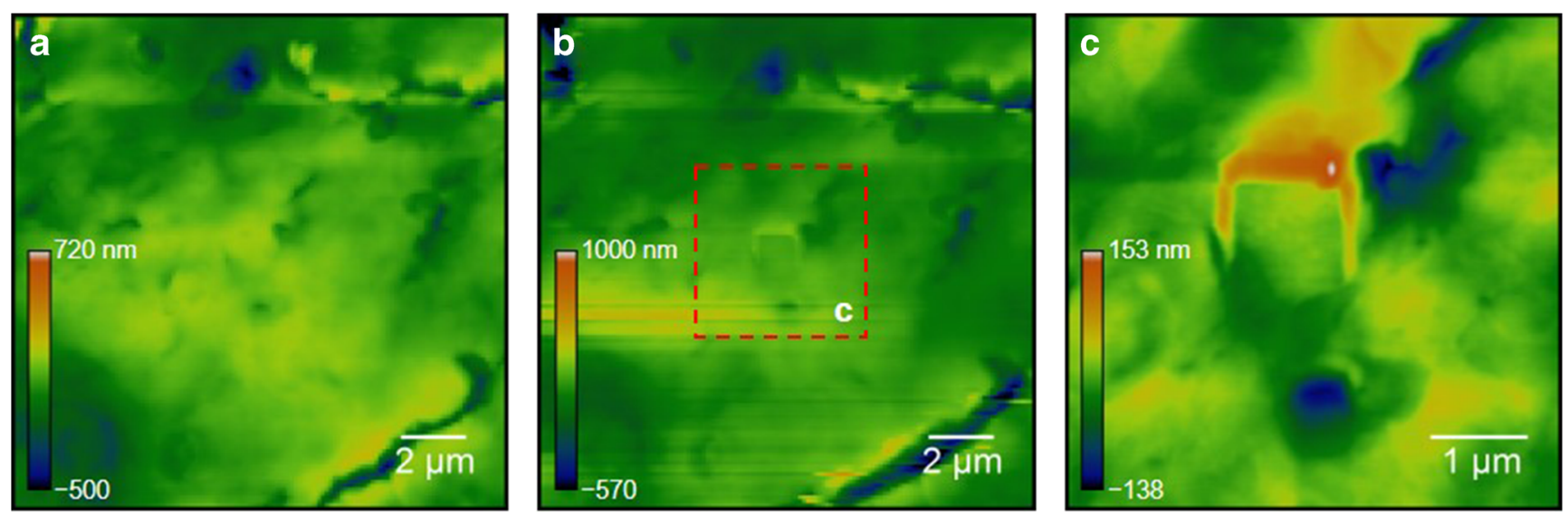

d

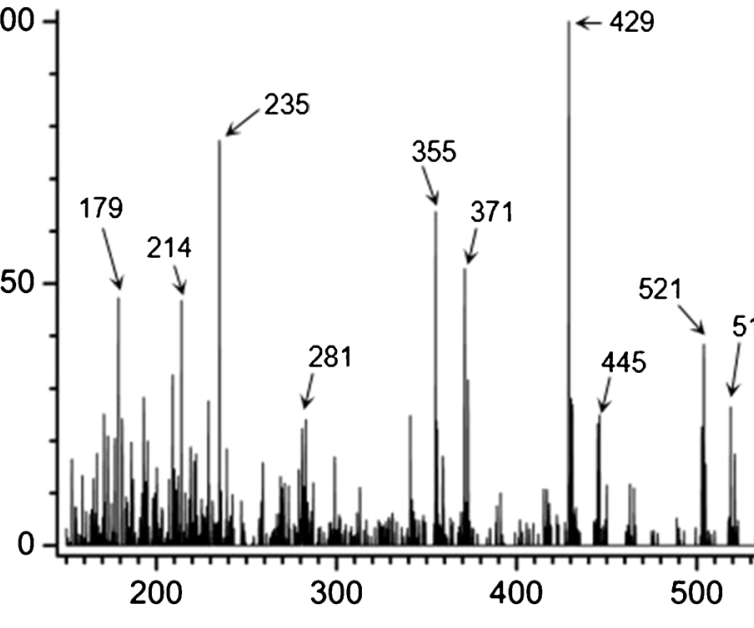

Fig. 4 Spatially resolved nanomechanical sampling of material from a mouse kidney thin tissue sample followed by photothermal desorption. Topography of kidney tissue (a) before and (b) after nanomechanical pick-up from 1- $\mu \mathrm{m}$ scan area with $3 \mu \mathrm{N}$ of force applied to the tip, (c) 
subtracted mass spectra from the $1 \mu \mathrm{m} \times 1 \mu \mathrm{m}$ sampled area in Fig. 4c can be seen in Fig. 4d. The rich mass spectra that are seen in Fig. 4d illustrate the benefit of TD of material from a small volume on the tip versus directly on the tissue. The abundance of higher mass ion above $500 \mathrm{Da}$ indicates the ability to preserve intact molecular species, avoiding melting and decomposition of the material that occurs during slow heat transfer processes when heating a sample directly as seen in Fig. S1 (see ESM).

\section{Discussion}

In this work, we report on a new method of nanomechanical sampling of materials from a surface using an AFM probe tip for real-time analysis directly from the tip using thermal desorption with secondary ionization on an AFM-MS platform. This approach allows for material to be concentrated directly onto the probe from areas down to $250 \mathrm{~nm} \times 250 \mathrm{~nm}$ and enables sampling of waxy and volatile materials that would not be amenable to direct thermal desorption or chemical analysis in a vacuum environment. We demonstrate the optimization metrics of the approach such as the collection efficiency as a function of cantilever force and scanned area. Overall, this approach allows heat to be transferred faster into a smaller sampled volume by minimizing on heat dissipation into the bulk material. This allows for a faster desorption and concentration of the gas phase analyte from a single heating pulse, thereby enabling more efficient sampling. Furthermore, improvements in heating pulses applied directly to the tip could enable the use of rapid heating of the material on the tip to improve the spatial resolution to sub-100 $\mathrm{nm}$ and desorb a much broader range of materials intact with molecular weight exceeding the 500-Da limit seen in standard thermal desorption experiments. Although currently the approach is more suited for profiling experiments due to the average data acquisition time per sampling, one could envision fast AFM scanning routines where each area could be scanned several times in under $10 \mathrm{~s}$ per sampling event to allow for mapping experiments in the future.

Acknowledgments This research was conducted at the Center for Nanophase Materials Sciences, which is a DOE Office of Science User Facility. Gary J. Van Berkel is thanked for helpful discussions of the data.

\section{Compliance with ethical standards}

Healthy mouse kidneys were obtained from Maastricht University in accordance with protocols approved by the Animal Care and Use Committee under Animal Experiment Committee (DEC) number 2016006 AVD107002016720.

Conflict of interest The authors declare that they have no competing interests.

\section{References}

1. Belianinov A, Ievlev AV, Lorenz M, Borodinov N, Doughty B, Kalinin SV, et al. Correlated materials characterization via multimodal chemical and functional imaging. ACS Nano. 2018;12(12): 11798-818. https://doi.org/10.1021/acsnano.8b07292.

2. Schwamborn K, Caprioli RM. MALDI imaging mass spectrometry - painting molecular pictures. Mol Oncol. 2010;4(6):529-38. https://doi.org/10.1016/j.molonc.2010.09.002.

3. Massonnet P, Heeren RMA. A concise tutorial review of TOFSIMS based molecular and cellular imaging. J Anal Atom Spectrom. 2019;34(11):2217-28. https://doi.org/10.1039/ C9JA00164F.

4. Feider CL, Krieger A, DeHoog RJ, Eberlin LS. Ambient ionization mass spectrometry: recent developments and applications. Anal Chem. 2019;91(7):4266-90. https://doi.org/10.1021/acs.analchem. $9 \mathrm{~b} 00807$.

5. Ovchinnikova OS, Kertesz V, Van Berkel GJ. Molecular surface sampling and chemical imaging using proximal probe thermal desorption/secondary ionization mass spectrometry. Anal Chem. 2011;83(2):598-603. https://doi.org/10.1021/ac102766w.

6. Ovchinnikova OS, Kjoller K, Hurst GB, Pelletier DA, Van Berkel GJ. Atomic force microscope controlled topographical imaging and proximal probe thermal desorption/ionization mass spectrometry imaging. Anal Chem. 2014;86(2):1083-90. https://doi.org/10. 1021/ac4026576.

7. Ovchinnikova OS, Nikiforov MP, Bradshaw JA, Jesse S, Van Berkel GJ. Combined atomic force microscope-based topographical imaging and nanometer-scale resolved proximal probe thermal desorption/electrospray ionization-mass spectrometry. ACS Nano. 2011;5(7):5526-31. https://doi.org/10.1021/nn200939e.

8. Ovchinnikova OS, Tai T, Bocharova V, Okatan MB, Belianinov A, Kertesz V, et al. Co-registered topographical, band excitation nanomechanical, and mass spectral imaging using a combined atomic force microscopy/mass spectrometry platform. ACS Nano. 2015;9(4):4260-9. https://doi.org/10.1021/acsnano.5b00659.

9. Ovchinnikova OS, Van Berkel GJ. Thin-layer chromatography and mass spectrometry coupled using proximal probe thermal desorption with electrospray or atmospheric pressure chemical ionization. Rapid Commun Mass Spectrom. 2010;24(12):1721-9. https://doi. org/10.1002/rcm.4551.

10. Somnath S, Jesse S, Van Berkel GJ, Kalinin SV, Ovchinnikova OS. Improved spatial resolution for spot sampling in thermal desorption atomic force microscopy - mass spectrometry via rapid heating functions. Nanoscale. 2017;9(17):5708-17. https://doi.org/10. 1039/C6NR09675A.

11. Hoffmann WD, Kertesz V, Srijanto BR, Van Berkel GJ (2017) Atomic force microscopy thermally-assisted microsampling with atmospheric pressure temperature ramped thermal desorption/ ionization-mass spectrometry analysis. Anal Chem 89(5):30363042

12. Price DM, Reading M, Hammiche A, Pollock HM. Micro-thermal analysis: scanning thermal microscopy and localised thermal analysis. Int J Pharm. 1999;192(1):85-96. https://doi.org/10.1016/ S0378-5173(99)00275-6.

13. Price DM, Reading M, Hammiche A, Pollock HM. New adventures in thermal analysis. J Therm Anal Calorim. 2000;60(3):723-33. https://doi.org/10.1023/A:1010137619071.

14. Price DM, Reading M, Lever TJ, Hammiche A, Pollock HM. Micro-thermal analysis and evolved gas analysis. Thermochim Acta. 2001;367-368:195-202. https://doi.org/10.1016/S00406031(00)00675-4.

15. Price DM, Reading M, Smith RM, Pollock HM, Hammiche A Localised evolved gas analysis by micro-thermal analysis. J Therm Anal Calorim. 
16. Reading M, Price DM, Grandy DB, Smith RM, Bozec L, Conroy $\mathrm{M}$, et al. Micro-thermal analysis of polymers: current capabilities and future prospects. Macromol Symp. 2001;167(1):45-62. https:// doi.org/10.1002/1521-3900(200103)167:1<45::AID-MASY45>3. $0 . \mathrm{CO} ; 2-\mathrm{N}$.

17. Lorenz M, Wagner R, Jesse S, Marsh J, Mamak M, Proksch P, Ovchinnikova OS. Nanoscale mass spectrometry multimodal imaging via tip-enhanced photothermal desorption. 2020.

18. Philippoz J-M, Zenobi R, Zare RN. Pulsed heating of surfaces: comparison between numerical simulation, analytical models, and experiments. Chem Phys Lett. 1989;158(1):12-7. https://doi.org/ 10.1016/0009-2614(89)87286-0.

19. Ghorai S, Seneviratne CA, Murray KK. Tip-enhanced laser ablation sample transfer for biomolecule mass spectrometry. J Am Soc Mass Spectrom. 2015;26(1):63-70. https://doi.org/10.1021/jasms. 8 b04869.

20. Lee D, Wetzel A, Bennewitz R, Meyer E, Despont M, Vettiger P, et al. Switchable cantilever for a time-of-flight scanning force microscope. Appl Phys Lett. 2004;84(9):1558-60. https://doi.org/10. $1063 / 1.1651641$

21. Wetzel A, Socoliuc A, Meyer E, Bennewitz R, Gnecco E, Gerber C. A versatile instrument for in situ combination of scanning probe microscopy and time-of-flight mass spectrometry. Rev Sci Instrum. 2005;76(10):103701. https://doi.org/10.1063/1.2082004.

22. Nikiforov MP, Gam S, Jesse S, Composto RJ, Kalinin SV. Morphology mapping of phase-separated polymer films using nanothermal analysis. Macromolecules. 2010;43(16):6724-30. https://doi.org/10.1021/ma1011254.

23. Nikiforov MP, Jesse S, Morozovska AN, Eliseev EA, Germinario LT, Kalinin SV. Probing the temperature dependence of the mechanical properties of polymers at the nanoscale with band excitation thermal scanning probe microscopy. Nanotechnology. 2009;20(39):395709. https://doi.org/10.1088/0957-4484/20/39/ 395709.

24. Lee J, Beechem T, Wright TL, Nelson BA, Graham S, King WP. Electrical, thermal, and mechanical characterization of silicon microcantilever heaters. J Microelectromech S. 2006;15(6):1644 55. https://doi.org/10.1109/JMEMS.2006.886020.

25. Wang J, Yan Y, Geng Y, Gan Y, Fang Z. Fabrication of polydimethylsiloxane nanofluidic chips under AFM tip-based nanomilling process. Nanoscale Res Lett. 2019;14(1):136. https:// doi.org/10.1186/s11671-019-2962-6.

26. Geng Y, Yan Y, Xing Y, Zhao X, Hu Z. Modelling and experimental study of machined depth in AFM-based milling of nanochannels. Int J Mach Tools Manuf. 2013;73(Complete):8796. https://doi.org/10.1016/j.ijmachtools.2013.07.001.

27. Shelley JT, Wiley JS, Hieftje GM. Ultrasensitive ambient mass spectrometric analysis with a pin-to-capillary flowing atmospheric-pressure afterglow source. Anal Chem. 2011;83(14): 5741-8. https://doi.org/10.1021/ac201053q.

28. Lee JK, Jansson ET, Nam HG, Zare RN. High-resolution live-cell imaging and analysis by laser desorption/ionization droplet delivery mass spectrometry. Anal Chem. 2016;88(10):5453-61. https://doi. org/10.1021/acs.analchem.6b00881.

29. Shelley JT, Badal SP, Engelhard C, Hayen H. Ambient desorption/ ionization mass spectrometry: evolution from rapid qualitative screening to accurate quantification tool. Anal Bioanal Chem. 2018;410(17):4061-76. https://doi.org/10.1007/s00216-018-1023-9.

Publisher's note Springer Nature remains neutral with regard to jurisdictional claims in published maps and institutional affiliations. 